\title{
A Systematic Review of Cerebral Arteriovenous Malformation Management
}

\author{
Karen Eliahu, ${ }^{1}$ Florence Hofman, ${ }^{2}$ Steven Giannotta. ${ }^{3}$
}

\begin{abstract}
Cerebral Arteriovenous Malformation is a neurovascular lesion characterized by an abnormal connection between arterial and venous systems, resulting in a tangle of blood vessels lacking intervening capillaries. The goal of treatment is to prevent catastrophic hemorrhage, neurological injury, or death. Despite the availability of multiple cutting-edge treatment options there is little consensus on the most promising approaches for treatment due to the novelty of each Arteriovenous Malformation case. This analysis will link the various angioarchitectural characteristics and associated presentations of Arteriovenous Malformation to treatment modalities. In the era of personalized medicine, genomics-driven research to normalize by drawing parallels between Cerebral Cavernous Malformation and Arteriovenous Malformation, both of which are characterized by hemorrhage-prone vascular malformations, may provide insight for the development of pharmacological therapy. Understanding the underlying mechanisms and genes responsible for the symptoms will allow us to better treat patients in a non-invasive manner and paves future directions in Arteriovenous Malformation treatment.
\end{abstract}

Key words: Intracranial Arteriovenous Malformations, Hemangioma, Cavernous, Central Nervous System, Precision Medicine, Gene Knockout Techniques, Patient Selection (Source: MeSH-NLM).

About the Author: Karen is recent Human Development and Aging University of Southern California, Los Angeles, United States and Provost's Undergraduate Provost's Undergraduate school of Medicine, Los Angeles, United States. She is also a recipient of the Research Discovery scholar

\section{Introduction}

Symptom heterogeneity of a single disease is one of the most compelling aspects of medicine. This phenomenon requires a case-by-case analysis of each patient as well as a novel approach for treatment. Brain Arteriovenous Malformation (AVM) illustrates this concept due the diversity in structure of the vascular lesions. Detection of AVM frequently occurs in acute situations; at the time of diagnosis approximately twothirds of patients present with intracranial hemorrhage, $15 \%$ of patients are asymptomatic and about $20 \%$ experience seizures highlighting the lack of a "typical" presentation. 1-3

Variable factors such as the location, size, and angioarchitecture of the tangle of blood vessels (nidus) pose a significant challenge for diagnosis and treatment. These connections that make up the nidus are problematic as they result in high-flow circulatory shunting of blood from arterial to venous systems, leading to hemodynamic abnormalities which are the origin of disease. ${ }^{1,4}$

\section{Methods}

In this review, a variety sources were synthesized to explore our current knowledge of the treatment and management of AVM as well as information about future directions for treatment. The PubMed Database was searched for significant studies and relevant discussions from peer reviewed journals in the field of AVM. Searched terms included: Intracranial Arteriovenous Malformations, Hemangioma, Cavernous, Central Nervous System, Cerebral Angiography, Endothelial Cells, Endovascular Procedure, Gene Knockout Techniques, Intracranial Hemorrhage, Microsurgery, MicroRNAs, and Radiosurgery. References of sources were used to identify additional sources. Relevant discussions included longstanding questions about the value of therapeutic abstention and more recent discussions about patient selection and the value of using newer endovascular techniques or Gamma Knife radiosurgery over the older traditional surgical techniques. As these questions evolved over time several opinions emerged to answer these difficult questions. As a result, we included traditional opinions that have played a large impact in the determination of standard of care and recent opinions ranging from 1986-2016. Furthermore, to provide a solid background about the epidemiology of the disease we found it useful to include a variety of sources because of the widespread disagreement on statistical figures associated with AVM. Sources from 1966-2016 were used and sources that followed several hundreds of patients were given value because of the lack of this type of large scale study.

AVM research is underdeveloped with fewer long-term and large-scale studies when compared to similar the number of studies existing for similar vascular malformations and as a result a wider net must be cast to ensure an accurate representation of statistical figures. When discussing recent and future research directions such as normalizing vasculature and using gene knockout techniques we included sources from 2000-2016 as sources and focused literature search to several studies whose main purpose was to normalize vasculature. Studies that included but did not primarily focus on normalizing vasculature were excluded. To minimize the risk of bias, several conflicting opinions were chosen when discussing popular debates in AVM treatment such as therapeutic abstention and patient selection. Varying opinions about statistical figures were also used and noted in the epidemiology section and sections

${ }^{1}$ Human Development and Aging, Davis School of Gerontology, University of Southern California, Los Angeles, United States of America.

${ }^{2}$ Department of Pathology, Keck School of Medicine, University of Southern California, Los Angeles, United States of America.

${ }^{3}$ Department of Neurosurgery, University of Southern California, Los Angeles, California, United States of America. 


\section{Review}

examining the link between angioarchitecture characteristics and clinical presentation in order to fairly and accurately examine multiple angles of these important discussion. Papers in English or papers with an English translation were chosen.

\section{Related Disorders}

Cerebral Cavernous Malformations (CCMs) are vascular lesions that are characterized by slow low perfusion and are known to be angiographically occult. ${ }^{5}$ Dural arteriovenous fistulas consist of fistulas between dural arteries and dural veins or venous sinuses and may contribute to the development of tinnitus and high-flow vascular shunts leading to hemorrhage risk. 6, 7 Pial arteriovenous fistulas are characterized by single or multiple pial or cortical arterial connections to a single venous channel and differ from AVMs by the lack of a true nidus. ${ }^{8}$

Cerebral Proliferative Angiopathy is identified by the presence of several small arterial feeding vessels and draining veins with normal brain parenchyma observed in-between abnormal vessels of the nidus. 9 Moyamoya Disease is defined as a progressive stenosis or occlusion of the internal carotid artery often leading to ischemic effects that cause development of a characteristic collateral network of vessels resembling a puff of smoke which translates to "moyamoya" in Japanese to compensate for reduced cerebral perfusion. ${ }^{10}$ Vein of Galen aneurysmal malformation angiopathy is characterized by one or more arteriovenous shunts that drain into a dilated vein of Markowski, the embryonic precursor to the Vein of Galen, often resulting in heart failure in the pediatric population. ${ }^{11}$

\section{Epidemiology}

The incidence of AVM is approximately 1 in 100,000, the prevalence is approximately 18 in 100,000, and the annual fatality risk is $1-1.5 \%$; these values are approximations as a large number of asymptomatic patients are not accounted for. $1,12,13$ The crude annual risk of a hemorrhage is about $2-4 \%$. ${ }^{2}$, ${ }^{14-20}$ Great variability of individual fatality risk exists due to AVM characteristics such as arterial feeding blood flow and venous drainage pattern. Each hemorrhage a patient experiences may severely impact quality of life and basic functionality.

AVMs are the leading cause of non-traumatic intracerebral hemorrhage in individuals aged younger than 35 years old. ${ }^{21}$ There exists, however, much disagreement about the proportion of strokes and hemorrhage that AVMs cause, some estimates account AVMs as the cause of $1 \%$ to up to one-third of strokes and $4 \%$ to one-third of primary intracerebral hemorrhage in adults. 1, 2, 4, 12, 17 Recurrent hemorrhage is an ongoing risk of AVM and is estimated to be as high as $17-18 \%$ in the first year although some suggest lower rate of risk.1, 17, 20 Morbidity resulting from rupture has been reported to be as high as $53 \%$ to $81 \%$ and mortality has been noted from $10 \%$ to $17.6 \%$ highlighting the need for early detection, treatment of AVM prior to rupture, as well as increasingly effective methods to treat rupture. ${ }^{14,} 22,23$ of all AVM-related hemorrhages, $63 \%$ are intraparenchymal, $32 \%$ are subarachnoid, and $6 \%$ are intraventricular. ${ }^{24}$

Female gender is associated with significant hemorrhage risk while male gender is associated with presentation of seizures. ${ }^{25}$, ${ }^{26}$ The mean age of diagnosis is $27.9-32$ years and hemorrhage risk peaks at a younger age (29 years and below).26, 27 Hemorrhage risk decreases over time except after the age of 60 where it begins to increase. ${ }^{26}$ Non-white race is significantly associated with hemorrhagic presentation as well. ${ }^{27}$

\section{Genetic Influences in AVM}

Hereditary hemorrhagic telangiectasia (HHT), also known as osler-Weber-Rendu syndrome, is an autosomal dominant genetic disease associated with a spectrum of vascular malformations. 28,29 Nine to $16 \%$ of patients with HHT are diagnosed with brain AVMs. ${ }^{29}$ Patients diagnosed with HHT1 have a higher prevalence of brain AVMs than the general population and patients with other types of HTT. ${ }^{28}$ Generally AVMs occur sporadically; only $2 \%$ are familial. $30-33$

AVM is caused by TCF- $\beta$ (Transforming growth factor beta) genes experiencing a loss of function mutation; these genes are implicated in cell proliferation, differentiation, morphogenesis, tissue homeostasis, regeneration, and epithelial-mesenchymal transition. ${ }^{13,34-37}$ A mutation in endoglin, a gene involved in angiogenesis, is the cause of type 1 hereditary hemorrhagic telangiectasia $\left(H_{H T}\right) .^{28}$ Endoglin encodes an accessory protein of TGF- $\beta$ receptor complexes. ${ }^{13}$ Type 2 hereditary hemorrhagic telangiectasia (HHT2) is characterized by a mutation in activinlike kinase 1 (ALK1, or ACVLR1), which codes for a transmembrane kinase also suspected to participate in the TGF$\beta$ signaling pathway. ${ }^{13}$

\section{Pathophysiology}

Understanding the angioarchitecture of AVMs is vital to the investigation of the etiology of associated hemorrhage, arguably the most concerning pathophysiologic symptom. The anomalous tangle of vessels results in irregular blood flow such that high blood flow is initiated in the feeding artery and carries through directly to the vein causing complications as veins are characteristically low pressure blood vessels. ${ }^{38}$ The lack of capillaries allows shunting of blood at a high speed and volume from the arterial system to the venous system. This consequent irregular blood flow results in weaknesses in blood vessel junctions, without the dissipation of pressure in the capillary system which results in risk of aneurysm development and rupture.39 Further complications arise because nidus vessel walls are often thin and constituent arteries lack a muscularis layer; as a result blood flow cannot be regulated within the artery. 23,40

Often shunting results in diversion of arterial supply to local brain tissue known as "steal" phenomena which may result debilitating ischemia and life-threatening hemorrhagic stroke. ${ }^{23,40}$

\section{Clinical Presentation}

Diagnosed AVMs may present with intracranial hemorrhage (experienced by $43.4 \%$ of patients), seizure (17.3\%), and headache $(24.9 \%) .3,41$ Clinical outcomes are unique to each patient and are subject to nidus characteristics. Studied relationships exists between angioarchitectural characteristics and clinical symptoms (Table 1).

$66 \%$ of AVM patients experience documented learning disorders which suggests the potential benefit of addressing functional cerebral deficits as a possible symptom to look for in the diagnosis process. ${ }^{23}$ Although not every symptom associated with AVM will lead to an AVM diagnosis, some symptoms such as unexplained delays in learning may serve as a signal for physician to utilize additional diagnostic methods, such as imaging, for further investigation.

\section{Diagnostic Imaging}

Radioanatomic characterization of AVM through imaging yields important information that impacts the selection of treatment modality. 3,42 As imaging has improved over time, diagnosis of AVMs has increased, creating additional challenges for treatment as a variety of AVMs are uncovered, often coincidentally. ${ }^{43}$ 
Table 1. Relationship between Angioarchitectural Characteristics and Symptoms.

\begin{tabular}{|c|c|}
\hline Clinical Symptom & Angioarchitectural Characteristics \\
\hline Intracranial hemorrhage & $\begin{array}{l}\text { Intranidal aneurysm, venous stenosis, } \\
\text { exclusive deep venous drainage, single } \\
\text { draining vein, high feeding mean } \\
\text { arterial pressure, small nidus size } \\
\text { deep location* } \\
\text { 80, 81 }\end{array}$ \\
\hline $\begin{array}{l}\text { Cardiac insufficiency or } \\
\text { developmental delay in children }\end{array}$ & High-flow shunting ${ }^{82,83}$ \\
\hline Dementia & $\begin{array}{l}\text { Increased vascular resistance secondary } \\
\text { to a long draining vein }{ }^{18}\end{array}$ \\
\hline $\begin{array}{l}\text { Seizures } \\
\text { Clinical symptom }\end{array}$ & $\begin{array}{l}\text { Venous varices in venous drainage }{ }^{84} \\
\text { Angioarchitectural Characteristics }\end{array}$ \\
\hline Intracranial hemorrhage & $\begin{array}{l}\text { Intranidal aneurysm*, venous stenosis, } \\
\text { exclusive deep venous drainage, single } \\
\text { draining vein, high feeding mean } \\
\text { arterial pressure, small nidus size } \\
\text { deep location }{ }^{\star 80,81}\end{array}$ \\
\hline $\begin{array}{l}\text { Cardiac insufficiency or } \\
\text { developmental delay in children }\end{array}$ & High-flow shunting ${ }^{82,83}$ \\
\hline Dementia & $\begin{array}{l}\text { Increased vascular resistance secondary } \\
\text { to a long draining vein }{ }^{18}\end{array}$ \\
\hline Seizures & Venous varices in venous drainage ${ }^{84}$ \\
\hline
\end{tabular}

Computerized tomography is used as a confirmation tool for identifying the location and extent of a hemorrhage. ${ }^{3}$ Magnetic resonance imaging provides the greatest visualization that illustrates the relationship between the lesion and the local brain tissue adjacent to the nidus.3, 42, 43 Arterial spin labeling magnetic resonance imaging is often used to diagnose arteriovenous shunts without true nidus to determine if the vascular abnormality is truly an AVM or if the lesion is indicative of a different disease. 38,44

Digital subtraction angiography is the gold standard for the evaluation of angioarchitecture of AVMs; It shows the following essential features: the feeding arteries, location of nidus, draining veins, morphology, presence, and location of associated aneurysms, venous varices, and vasculopathic stenotic segments on arteries and veins.3, 38, 42, 43

\section{Therapeutic abstention}

Therapeutic abstention is proposed for asymptomatic multiple AVMs discovered incidentally without angiographic bleeding risk and in some cases where the nidus exists in eloquent areas. 45 Therapeutic abstention is often coupled with management of hypertension, conventional regimens for headaches, anticonvulsant medication to manage seizures and routine monitoring with surveillance imaging .42, 43

In acutely ruptured AVMs, temporary therapeutic abstention is crucial for healing before implementing invasive treatment options. ${ }^{4}$ It is standard to wait a month or longer to allow for patient recovery, hematoma liquefaction, and inflammatory reactions to subside. 4 The only exception to the guideline is for superficial low Spetzler-Martin grade AVMs with elucidated angioarchitecture where it is feasible to perform a hematoma evacuation and excision of the nidus simultaneously. ${ }^{4}$

The Spetzler-Martin scale is a grading system used to predict surgical resection risk based on the nidus size, venous drainage pattern, and location in relation to eloquent cortex (site includes sensorimotor, language, visual cortex, hypothalamus, thalamus, internal capsule, brainstem, cerebellar peduncles, and cerebellar nuclei. 3, 43, 46 Higher grades are associated with greater surgical morbidity and mortality. 42, 43, 46

The ARUBA Study: A Randomized Trial of Unruptured Brain AVMS (ARUBA) played a large role in determining whether it is worthwhile to treat AVMs based on the risks of the various treatment options available. The Rational for the ARUBA Study was designed to test the null hypothesis that treatment, by means of interventional procedures, surgery, or radiotherapy, offers no difference in the risk of death or symptomatic stroke, and no better functional outcome than does conservative management at 5 years from discovery of an unruptured brain AVM. 23, 47 The ARUBA Study findings are strongly oriented towards therapeutic abstention. ${ }^{48}$ It is difficult to predict patient prognosis for therapeutic abstention because the ARUBA study is subject to several experimental flaws. ${ }^{23,49,50}$

Selection bias remains an issue with the ARUBA trial design, while it is a randomized control trial, only those patients deemed by their physicians to have low risk of hemorrhage will be enrolled because the standard of care for a high hemorrhage risk patient is to implement a more invasive therapeutic modality, thus compromising the ability of the study to represent a generalized AVM patient population. ${ }^{23,42}$ It is suggested that if death or stroke occurs a few years following a multimodal treatment then the treatment was in only fact partially completed and is therefore an ineffective and dangerous method. ${ }^{48}$ It has been thought, contrary to the findings of the ARUBA study, that microsurgery, specifically on unruptured lesions smaller than $3 \mathrm{~cm}$ or on Spetzler-Martin Grade I and II lesions, leads to better outcomes when compared to therapeutic abstention or conservative treatments. ${ }^{51}$ This finding was credited to well-selected microsurgical cases and suggests that improved patient selection will lead to improved outcomes. 51

\section{Treatment}

AVMs are heterogeneous pathological entities and therefore require a unique multidisciplinary approach for treatment. ${ }^{23}$ Accurate assessment of risk associated with treatment is crucial for achieving the best outcomes for patients. ${ }^{52}$ Comparison of treatments must take into account the associated benefits and risks of each, is outlined in Table 2 . The risk of rupture has become the driving force for using multimodal therapies involving microsurgical resection, stereotactic radiotherapy, and endovascular embolization to obliterate lesions. ${ }^{23}$

\section{Endovascular Embolization}

Advances in endovascular technologies, including microcatheter design, and the development of liquid embolics with unique properties, have increased popularity of endovascular treatment, enabling the delivery of therapy despite the structural complexity of tangled blood vessels. ${ }^{42}$

An almost all cases, preoperative embolization is performed before surgical resection or stereotactic radiotherapy..$^{18}$ Preoperative embolization is often used to reduce the size of an AVM for microsurgical excision; the $6.5 \%$ complication rate is deemed low enough for utilization of this method. ${ }^{18,43,53}$

The most frequently used agents include the liquid embolic agents; n-Butyl Cyanoacrylate (n-BCA) and Onyx (an ethylene vinyl alcohol copolymer), used to block blood flow before surgical treatment.23 Appropriate patient selection is key to an optimal embolization treatment that prevents recurrent hemorrhage. AVM characteristics must follow specific guidelines in order for the treatment to reduce risk of rupture and not create additional disability for the patient. Criteria for embolization includes a small nidus size. ${ }^{18}$ If a lesion exists within eloquent tissue, the role of endovascular therapy may be limited as the risk of stroke or ischemia may outweigh the benefits of treatment. ${ }^{18}$

Cases presenting with hemorrhage, deep venous drainage or associated aneurysms do not have a reduced risk of repeated rupture if only partially treated with this modality. ${ }^{41}$ 


\section{Review}

Endovascular techniques can be applied to occlude intranidal and distal flow-related aneurysms and used for 'sealing' a rupture site or focal angioarchitectural weakness when the area of interest can be easily identified and safely accessed. ${ }^{4}$

The advantages of endovascular therapy include immediate occlusion in some cases, intraprocedural angiographic evaluation, and the utilization of a variation of viscosities of embolic agents which may be used for diverse angioarchitectural characteristics.23, 42, 43 The disadvantages of endovascular therapy include the risks of partial embolization, unintended vessel embolization, intracranial hemorrhage, and normal perfusion pressure breakthrough, which may lead to edema or hemorrhage. 42, 43 As technology improves, this treatment modality may continue transition from a adjunctive therapy to a curative modality. ${ }^{23}$ Novel techniques such as the transvenous approach, modeled after successful treatment techniques for dural arteriovenous fistulas, may make it possible to treat difficult high-flow cases with solely endovascular techniques. 54

\section{Stereotactic Radiosurgery}

Gamma Knife radiosurgery (CKRS) is performed by administering sharply localized high-dose radiation to promote a vascular injury response with the goal of obliterating the vessel, a process often taking 1 to 2 years. ${ }^{42}$ GKRS's strength lies in its precision as it affords submillimeter targeting and allows treatment in deep locations of the brain with minimal radiation exposure to neighboring brain tissue. ${ }^{23}$

As a result of this treatment modality's timeline, this treatment is not appropriate in acutely ruptured AVMs as therapeutic effects may not appear until after a number of months. ${ }^{4}$ Small AVMs (less than $3-3.5 \mathrm{~cm}^{3}$ ) are optimal for treatment and diffuse AVMs pose a significant challenge as it becomes harder to minimize interspace parenchymal tissue exposure to radiation in. 42, $55 \mathrm{~A}$ multicenter analysis of 1255 patients receiving GKRS reported $8 \%$ of patients who developed a neurologic deficit after the radiation treatment as a result of edema and necrosis of

healthy brain tissue. ${ }^{42,56}$ Nevertheless, cure rates for AVMS treated with primary GKRS have been estimated at $80 \%$ at 2-year follow-up, highlighting the efficacy of GKRS as a less invasive solution than surgery to treating complexly shaped AVMs as well as AVMs in eloquent areas. ${ }^{23}$

\section{Microsurgical Resection}

Microsurgical resection with angiographic confirmation of obliteration are considered the gold standard of AVM treatment and are regarded as curative. 43,57 Microsurgical technique has improved over time and has solidified itself as the best choice for patients with cerebral AVM if angioarchitectural characteristics are appropriate (non-diffuse lesions) and if manipulation of the location near the nidus would not cause severe complications.3, 57 Symptoms often resolve dramatically following microsurgical resection of the AVM. ${ }^{3}$

The high rate of complete obliteration is the most notable advantage of this treatment modality, while the limitations of this approach include its invasiveness, anatomic accessibility, edema from retraction, intraoperative rupture, resection of normal brain tissue, feeding vessel thrombosis and infection risk. 3, 42, 43 A high cure rate has been associated with microsurgery in pediatric patients. ${ }^{8}$ Furthermore, patients with AVMs smaller than $3 \mathrm{~cm}^{3}$ experience better outcomes that include a lower rate of significant neurological deficits as a result of the surgery. ${ }^{51}$

\section{Pharmacological Intervention Normalizes AVM Vasculature to Reduce Hemorrhage Risk} Current AVM research sheds light on potential for targeted noninvasive therapeutic modalities that aim to normalize AVM vasculature which reduces hemorrhagic risk. 59 Normalization of the vasculature is achieved by normalizing the abnormal levels of growth factors in AVM brain endothelial cells (BECs). There are several differences between healthy brain endothelial cells and AVM-BECs that may unlock the key to developing additional specific therapies based on molecular mechanisms of AVMBECS.

Table 2. Relationship between Treatment Modalities and Angioarchitectural Characteristics.

\begin{tabular}{|c|c|c|}
\hline Endovascular embolization & $\begin{array}{l}\text { Multimodal approach that renders surgery technically } \\
\text { simpler or reduces size of large AVMs }{ }^{85,86}\end{array}$ & $\begin{array}{l}\text { Nidus with adjunct aneurysm(s) } 55 \text {, multiple draining } \\
\text { veins (transvenous approach) } 54 \text {, small and medium } \\
\text { sized } A V M s^{87} \text {, AVMs in posterior fossa (multimodal } \\
\text { treatment) }{ }^{88}\end{array}$ \\
\hline Radiotherapy & $\begin{array}{l}\text { Effective as a standalone therapy, multimodal } \\
\text { approach for partially embolized small AVMs } 55,85,89\end{array}$ & $\begin{array}{l}\text { AVMs less than } 3-3.5 \mathrm{~cm}^{3} \text { in eloquent area }{ }^{42}, 55 \text {, less } \\
\text { than } 10-11 \mathrm{~cm}^{3} \text { in noneloquent area } 89 \text {, high marginal } \\
\text { dose of } 16-25 \mathrm{Cy} 55,89 \text {, smaller target volume } 55 \text {, fewer } \\
\text { draining veins } 55\end{array}$ \\
\hline Surgical resection & $\begin{array}{l}\text { Effective as curative modality }{ }^{58} \text {, multimodal approach } \\
\text { often following preoperative endovascular } \\
\text { embolization }{ }^{85}\end{array}$ & $\begin{array}{l}\text { AVMs smaller than } 3 \mathrm{~cm}^{3}{ }^{51} \text {, surgically accessible }{ }^{58} \text {, } \\
\text { superficial }{ }^{85} \text {, noneloquent area }{ }^{85} \text {, avoid deep draining } \\
\text { veins and high-flow shunts }{ }^{85}\end{array}$ \\
\hline
\end{tabular}

AVM-BECs have been found to exhibit functional abnormalities in migration and tubule formation resembling cells in active angiogenesis. 59 The role of vascular endothelial growth factor (VEGF), a crucial proangiogenic mediator, has also been studied in AVM-BECS and it has been found that these cells are demonstrated to be "activated" when compared to normal BECS. 59 AVM-BECs have increased proangiogenic cytokine secretion and proangiogenic receptor expression indicating that they exist in an abnormal vascular growth state. 59 The subsequent elevation in the secretion of VEGF stimulates survival, proliferation, and migration which in turn may contribute to clinical outcomes that contribute to the challenges in treating AVM. 59 Further study must be done to determine if the abnormal characteristics of AVM-BECS are a result of their inherent differences from normal BECS or if they are characteristics that developed as a reaction to abnormal blood flow and ischemia caused by the malformation itself. 59

One study was aimed at using microRNA-18a (miR-18a) as a therapeutic agent to improve AVM-BEC function. ${ }^{60} \mathrm{It}$ was found that the presence of miR-18a increased an important angiostatic factor that is downregulated in normal AVM-ECs production. ${ }^{12,60}$ Furthermore, miR-18a reduced VEGF levels which are both overexpressed in normal AVM-BECS, thus helping to normalize 
the vascular cells.60, 61 It was found by another study that upregulating thrombospondin- 1 in AVM-ECS normalizes the rate of proliferation, migration, and the efficiency of tubule formation causing the AVM-ECs to resemble normal ECs. ${ }^{61}$

Ago-2 has been found to act as a systemic miR-18a carrier which facilitates miR-18a entry into brain endothelial cells in-vitro and in-vivo. ${ }^{62}$ miR-18a, with the help of the Ago-2 delivery platform, have been shown to ameliorate key abnormal characteristics of AVM-BECs. ${ }^{60-62}$ There is potential to develop pharmacological treatment for AVM that targets AVM-BECs, a cell type common in all AVM lesions, as a non-invasive method that would be compatible with diverse angioarchitectural characteristics and may be especially beneficial to patients with AVMs in eloquent area where invasive treatments may not be suitable.

Additionally, Notch4, may be a compelling molecular target to normalize AVM cells. Notch 4 is a vascular angiogenesis regulator primarily found in endothelial cells and is implicated in initiation and maintenance of arteriovenous communications. ${ }^{63}$, ${ }^{64}$ In AVM, Notch 4 is found to be overexpressed by up to $35 \% .64$ Normalization of Notch4 by repressing Notch4 expression has been shown to regress high-flow arteriovenous shunts. ${ }^{40}$ This causes blood to return to capillaries resulting in a reversal of tissue hypoxia caused by "steal" phenomenon that often occurs in AVM. 40 Normalizing Notch 4 in endothelial cells may be the key to overcoming the challenge of treating a heterogeneous population of lesions.

\section{Drawing Parallels from Genetic Manipulations} in Cerebral Cavernous Malformation Research Recent strides in Cerebral Cavernous Malformation research using genetic manipulation in murine models may provide long awaited answers in AVM and may contribute to future development of pharmacological therapy for the disease. Cerebral Cavernous Malformation (CCM) is a vascular malformation that like AVM, is characterized by enlarged capillary cavities lacking intervening neural tissue and smooth muscle cells. ${ }^{65,66}$ Drawing parallels between CCM and AVM, both of which are characterized by hemorrhage-prone vascular malformations, may advance genomics-driven innovations within AVM research in the era of personalized medicine.

Normalizing CCM vasculature may be achieved by investigating the genes that cause abnormal vasculature. CCM vascular phenotype can be induced in murine models by endotheliumspecific loss-of-function mutations of either of the independent genes; $\mathrm{CCM}_{1}$ (also known as $\mathrm{KRIT}_{1}$ ) $\mathrm{CCM}_{2}$ (OSM) and $\mathrm{CCM}_{3}$ (PDCD 10). ${ }^{67-70}$ CCM3-deficient endothelium takes on mesenchy- mal- and stem-cell-like characteristics (EndMT) and as a result, the transforming growth factor (TGF- $\beta$ ) pathway becomes activated, contributing to the development of vascular malformations. 68, 70 The anti-inflammatory drugs sulindac sulfide and sulindac sulfone have been shown to reduce the number and size vascular malformations in $\mathrm{CCM}_{3}$-deficient cells by inhibiting TGF- $\beta .{ }^{68}$ Further studies have shown EndMT switch occurs in sporadic CCM patients and that therapeutic agents suggested for familial AVMs may be used for sporadic AVMs as well, broadening the scope of patients that can benefit from pharmacological intervention. ${ }^{71}$

Increased endothelial permeability is a hallmark of vascular disease correlated to neo-angiogenesis in injured tissues and congenital malformations such as HHT which is linked to AVM. $35,65,72,73$ LOSS of function mutations in $\mathrm{CCM}_{1}$ and $\mathrm{CCM}_{3}$ result in upregulation of Vascular Endothelial Growth Factor A (VEGFA) and VEGF receptor 2 causing an alteration in endothelial permeability in-vitro.65 Increased VEGF-A/VEGFR enables pathological angiogenesis and may contribute to increased symptomology by increased leakiness of blood vessels in the malformation leading to increased risk of hemorrhage. 65

Selective loss of $\mathrm{CCM}_{2}$ results in upregulation of Rho kinase which has been linked to loosened junctions and decreased tube formation in endothelial cells in vitro and loss of vascular integrity of endothelial cells in vivo.74-79 The $\mathrm{CCM}_{2}$ mutation also causes an increase in ADAMTS (a disintegrin and metalloproteinase with thrombospondin motifs) expression which is thought to breakdown a proteoglycan matrix essential in supporting blood vessels, contributing to the development of a cavernoma.79

Advancements made in CCM research using gene knockouts may serve as a model for how to approach unexplored avenues in AVM. Genetic analysis may reveal promising groups of genes to silence with the goal of reproducing AVM phenotype.

\section{Conclusion}

AVMs are heterogeneous entities that are often found incidentally and treated in acute situations which contributes to the lack of research and consensus on various treatment plans for unique cases. This review has outlined relationships between symptoms and angioarchitecture as well as relationships between treatment options and particular lesion characteristics. Limitations to this review include incomplete retrieval of information. Nevertheless, a holistic exploration of AVM was synthesized by a wide variety of sources to prevent this. 


\section{Review}

\section{References}

1. Al-Shahi R, Warlow C. A systematic review of the frequency and prognosis of arteriovenous malformations of the brain in adults. Brain. 2001; 124(Pt 10): 1900-26.

2. Brown RD, Jr., Wiebers DO, Forbes G, O'Fallon WM, Piepgras DC, Marsh WR, et al. The natural history of unruptured intracranial arteriovenous malformations. J Neurosurg. 1988; 68(3): 352-7.

3. Zhao J, Wang S, Li J, Qi W, Sui D, Zhao Y. Clinical characteristics and surgical results of patients with cerebral arteriovenous malformations. Surgical neurology. 2005; 63 2): 156-61; discussion 61

4. Martinez JL, Macdonald RL. Surgical Strategies for Acutely Ruptured Arteriovenous Malformations. Frontiers of neurology and neuroscience. 2015 37: $166-81$

5. Murakami K, Endo T, Tominaga T. An analysis of flow dynamics in cerebra cavernous malformation and orbital cavernous angioma using indocyanine green videoangiography. Acta Neurochir (Wien). 2012; 154(7): 1169-75.

6. Cupta A, Periakaruppan A. Intracranial dural arteriovenous fistulas: A Review. Indian I Radiol Imaging. 2009; 19(1): 43-8.

7. Pabaney AH, Robin AM, Basheer A, Malik G. Surgical Management of Dura Arteriovenous Fistula After Craniotomy: Case Report and Review of Literature. World neurosurgery. 2016; 89: 731 e7- e11.

8. Lee JY, Son YJ, Kim JE. Intracranial pial arteriovenous fistulas. J Korean Neurosurg Soc. 2008; 44(2): 101-4.

9. Rohit, Goh PS. Diffuse Proliferative Cerebral Angiopathy: A case report and review of the literature. J Radiol Case Rep. 2015; 9(9): 1-10.

10. Cuey S, Tournier-Lasserve E, Herve D, Kossorotoff M. Moyamoya disease and syndromes: from genetics to clinical management. Appl Clin Cenet. 2015; 8: $49-68$.

11. Pearl M, Gomez J, Gregg L, Gailloud P. Endovascular management of vein of Galen aneurysmal malformations. Influence of the normal venous drainage on the choice of a treatment strategy. Childs Nerv Syst. 2010; 26(10): 1367-79. 12. Berman MF, Sciacca RR, Pile-Spellman J, Stapf C, Connolly ES, Jr., Mohr $\mathrm{JP}$, et al. The epidemiology of brain arteriovenous malformations. Neurosurgery. 2000; 47(2): 389-96; discussion 97.

13. Kim H, Su H, Weinsheimer S, Pawlikowska L, Young WL. Brain arteriovenous malformation pathogenesis: a response-to-injury paradigm. Acta Neurochir Suppl. 2011; 111: 83-92.

14. Carl J. Graf, Ceorge E. Perret, James C. Torner. Bleeding from cerebral arteriovenous malformations as part of their natural history. Journal of Neurosurgery. 1983; 58(3): 331-7.

15. Crawford PM, West CR, Chadwick DW, Shaw MD. Arteriovenous malformations of the brain: natural history in unoperated patients. J Neurol Neurosurg Psychiatry. 1986; 49(1): 1-10.

16. Forster DM, Steiner L, Hakanson S. Arteriovenous malformations of the brain. A long-term clinical study. I Neurosurg. 1972; 37(5): 562-70.

17. Mast H, Young WL, Koennecke HC, Sciacca RR, Osipov A, Pile-Spellman J, et al. Risk of spontaneous haemorrhage after diagnosis of cerebral arteriovenous malformation. Lancet. 1997; 350(9084): 1065-8.

18. Radvany MG, Gregg L. Endovascular treatment of cranial arteriovenous malformations and dural arteriovenous fistulas. Neurosurgery clinics of North America. 2012; 23(1): 123-31.

19. Stephen L. Ondra, Henry Troupp, Eugene D. Ceorge, Karen Schwab. The natural history of symptomatic arteriovenous malformations of the brain: a 24-year follow-up assessment. Journal of Neurosurgery. 1990; 73(3): 387-91.

20. Youichi Itoyama, Syouzaburou Uemura, Yukitaka Ushio, Jun-Ichi Kuratsu, Nobuhito Nonaka, Hidetaka Wada, et al. Natural course of unoperated intracranial arteriovenous malformations: study of 50 cases. Journal of Neurosurgery. 1989; 71(6): 805-9.

21. Ruiz-Sandoval JL, Cantu C, Barinagarrementeria F. Intracerebral hemorrhage in young people: analysis of risk factors, location, causes, and prognosis. Stroke; a journal of cerebral circulation. 1999; 30(3): 537-41.

22. Perret $\mathrm{G}$, Nishioka $\mathrm{H}$. Report on the cooperative study of intracranial aneurysms and subarachnoid hemorrhage. Section Vl. Arteriovenous malformations. An analysis of 545 cases of cranio-cerebral arteriovenous malformations and fistulae reported to the cooperative study. I Neurosurg. 1966; 25(4): 467-90.

23. Yashar P, Amar AP, Giannotta SL, Yu C, Pagnini PG, Liu CY, et al. Cerebral arteriovenous malformations: issues of the interplay between stereotactic radiosurgery and endovascular surgical therapy. World neurosurgery. 2011, 75(5-6): 638-47

24. HööK 0, Johanson C. Intracranial arteriovenous aneurysms: A follow-up study with particular attention to their growth. AMA Archives of Neurology $\&$ Psychiatry. 1958; 80(1): 39-54.

25. Ecker RD. Epistemology of Brain Arteriovenous Malformations. World neurosurgery. 2016; 89: 697-8.

26. Tong X, Wu J, Lin F, Cao Y, Zhao Y, Ning B, et al. The Effect of Age, Sex, and Lesion Location on Initial Presentation in Patients with Brain Arteriovenous Malformations. World neurosurgery. 2016; 87: 598-606.

27. Yang W, Caplan JM, Ye X, Wang JY, Braileanu M, Rigamonti D, et al. Racial Associations with Hemorrhagic Presentation in Cerebral Arteriovenous Malformations. World neurosurgery. 2015; 84(2): 461-9.

28. Choi EJ, Chen W, Jun K, Arthur HM, Young WL, Su H. Novel brain arteriovenous malformation mouse models for type 1 hereditary hemorrhagic telangiectasia. PLoS One. 2014; 9(2): e88511.
29. Nishida T, Faughnan ME, Krings T, Chakinala M, Cossage JR, Young WL, et al. Brain arteriovenous malformations associated with hereditary hemorrhagic telangiectasia: gene-phenotype correlations. Am J Med Cenet A. 2012; 158A(11): 2829-34

30. Letteboer TG, Mager IJ, Snijder RJ, Koeleman BP, Lindhout D, Ploos van Amstel JK, et al. Cenotype-phenotype relationship in hereditary haemorrhagic telangiectasia. J Med Cenet. 2006; 43(4): 371-7.

31. Matsubara S, Mandzia JL, ter Brugge K, Willinsky RA, Faughnan ME. Angiographic and clinical characteristics of patients with cerebral arteriovenous malformations associated with hereditary hemorrhagic telangiectasia. AJNR Am J Neuroradiol. 2000; 21(6): 1016-20.

32. Raj J, Stoodley M. Experimental Animal Models of Arteriovenous Malformation: A Review. Veterinary Sciences. 2015; 2(2): 97.

33. Willinsky RA, Lasjaunias $P$, Terbrugge K, Burrows P. Multiple cerebral arteriovenous malformations (AVMs). Review of our experience from 203 patients with cerebral vascular lesions. Neuroradiology. 1990; 32(3): 207-10. 34. Arthur HM, Ure J, Smith A], Renforth G, Wilson DI, Torsney E, et al. Endoglin, an ancillary TCFbeta receptor, is required for extraembryonic angiogenesis and plays a key role in heart development. Dev Biol. 2000; $217(1): 42-53$.

35. Marchuk DA, Srinivasan S, Squire TL, Zawistowski JS. Vascular morphogenesis: tales of two syndromes. Hum Mol Cenet. 2003; 12 Spec No 1: R97-112.

36. Massague J. TCFbeta signalling in context. Nat Rev Mol Cell Biol. 2012; 13(10): 616-30.

37. Tual-Chalot S, Oh SP, Arthur HM. Mouse models of hereditary hemorrhagic telangiectasia: recent advances and future challenges. Front Cenet. 2015; 6: 25

38. March BT, Jayaraman MV. Aneurysms, arteriovenous malformations, and dural arteriovenous fistulas: diagnosis and treatment. Seminars in roentgenology. 2014; 49(1): 10-21.

39. Mouchtouris N, Jabbour PM, Starke RM, Hasan DM, Zanaty M, Theofanis $\mathrm{T}$, et al. Biology of cerebral arteriovenous malformations with a focus on inflammation. J Cereb Blood Flow Metab. 2015; 35(2): 167-75.

40. Murphy PA, Kim TN, Huang L, Nielsen CM, Lawton MT, Adams RH, et al. Constitutively active Notch4 receptor elicits brain arteriovenous malformations through enlargement of capillary-like vessels. Proceedings of the National Academy of Sciences of the United States of America. 2014; 111(50): 18007-12.

41. da Costa L, Wallace MC, Ter Brugge KG, O'Kelly C, Willinsky RA, Tymiansk $M$. The natural history and predictive features of hemorrhage from brain arteriovenous malformations. Stroke; a journal of cerebral circulation. 2009; 40(1): 100-5

42. Novakovic RL, Lazzaro MA, Castonguay AC, Zaidat 00 . The diagnosis and management of brain arteriovenous malformations. Neurol Clin. 2013; 31(3): $749-63$.

43. Ajiboye N, Chalouhi N, Starke RM, Zanaty M, Bell R. Cerebra arteriovenous malformations: evaluation and management. ScientificWorldjournal. 2014; 2014: 649036

44. Paramasivam S, Toma N, Niimi Y, Berenstein A. Development, clinical presentation and endovascular management of congenital intracranial pial arteriovenous fistulas. J Neurointerv Surg. 2013; 5(3): 184-90.

45. Robert $T$, Blanc $R$, Botta $D$, Ciccio $G$, Smajda $S$, Redjem $H$, et al. Management of multiple cerebral arteriovenous malformations in a nonpediatric population. Acta Neurochir (Wien). 2016.

46. Spetzler RF, Martin NA. A proposed grading system for arteriovenous malformations. J Neurosurg. 1986; 65(4): 476-83.

47. Stapf C. The rationale behind "A Randomized Trial of Unruptured Brain AVMs" (ARUBA). Acta Neurochir Suppl. 2010; 107: 83-5.

48. Cenzato M, Delitala A, Delfini R, Pasqualin A, Maira G, Esposito V, et al. Position statement from the Italian Society of Neurosurgery on the ARUBA Study. J Neurosurg Sci. 2016; 60(1): 126-30.

49. Cockroft KM. Unruptured brain arteriovenous malformations should be treated conservatively: no. Stroke; a journal of cerebral circulation. 2007; 38(12): 3310-1.

50. Cockroft KM. Unruptured cerebral arteriovenous malformations: to treat or not to treat. Stroke; a journal of cerebral circulation. 2006; 37(5): 1148-9. 51. Schramm J, Schaller K, Esche J, Bostrom A. Microsurgery for cerebral arteriovenous malformations: subgroup outcomes in a consecutive series of 288 cases. J Neurosurg. 2016: 1-8.

52. Conger A, Kulwin C, Lawton MT, Cohen-Cadol AA. Diagnosis and evaluation of intracranial arteriovenous malformations. Surg Neurol Int. 2015; 6: 76

53. Ledezma CJ, Hoh BL, Carter BS, Pryor JC, Putman CM, Ogilvy CS Complications of cerebral arteriovenous malformation embolization: multivariate analysis of predictive factors. Neurosurgery. 2006; 58(4): 602-11; discussion -11 ,

54. Choudhri 0, Ivan ME, Lawton MT. Transvenous Approach to Intracranial Arteriovenous Malformations: Challenging the Axioms of Arteriovenous Malformation Therapy? Neurosurgery. 2015; 77(4): 644-51; discussion 52. 55. Diaz 0, Scranton R. Endovascular treatment of arteriovenous malformations. Handb Clin Neurol. 2016; 136: 1311-7.

56. Flickinger JC, Kondziolka D, Lunsford LD, Pollock BE, Yamamoto M, Corman DA, et al. A multi-institutional analysis of complication outcomes after 
arteriovenous malformation radiosurgery. Int | Radiat Oncol Biol Phys. 1999; 44(1): 67-74.

57. Pradilla G, Coon AL, Huang J, Tamargo RJ. Surgical treatment of cranial arteriovenous malformations and dural arteriovenous fistulas. Neurosurgery clinics of North America. 2012; 23(1): 105-22.

58. Reitz M, von Spreckelsen N, Vettorazzi E, Burkhardt T, Crzyska U, Fiehler J, et al. Angioarchitectural Risk Factors for Hemorrhage and Clinical Long-Term Outcome in Pediatric Patients with Cerebral Arteriovenous Malformations. World neurosurgery. 2016; 89: 540-51.

59. Jabbour MN, Elder JB, Samuelson CG, Khashabi S, Hofman FM, Ciannotta SL, et al. Aberrant angiogenic characteristics of human brain arteriovenous malformation endothelial cells. Neurosurgery. 2009; 64(1): 139-46; discussion 46-8.

60. Ferreira R, Santos T, Amar A, Tahara SM, Chen TC, Giannotta SL, et al. MicroRNA-18a improves human cerebral arteriovenous malformation endothelial cell function. Stroke; a journal of cerebral circulation. 2014; 45(1): 293-7.

61. Stapleton Cl, Armstrong DL, Zidovetzki R, Liu CY, Giannotta SL, Hofman FM. Thrombospondin-1 modulates the angiogenic phenotype of human cerebral arteriovenous malformation endothelial cells. Neurosurgery. 2011; 68(5): 1342-53; discussion 53

62. Ferreira R, Santos T, Amar A, Cong A, Chen TC, Tahara SM, et al. Argonaute-2 promotes miR-18a entry in human brain endothelial cells. J Am Heart Assoc. 2014; 3(3): e000968.

63. Nijjar SS, Crosby HA, Wallace L, Hubscher SG, Strain AJ. Notch receptor expression in adult human liver: a possible role in bile duct formation and hepatic neovascularization. Hepatology. 2001; 34(6): 1184-92.

64. Tu J, Li Y, Hu Z. Notch 1 and 4 signaling responds to an increasing vascular wall shear stress in a rat model of arteriovenous malformations. Biomed Res Int. 2014; 2014: 368082.

65. DiStefano PV, Kuebel IM, Sarelius IH, Glading AJ. KRIT1 protein depletion modifies endothelial cell behavior via increased vascular endothelial growth factor (VECF) signaling. J Biol Chem. 2014; 289(47): 33054-65.

66. Yang IY, Yum MS, Kim EH, Choi HW, Yoo HW, Ko TS. Two cases of familial cerebral cavernous malformation caused by mutations in the $\mathrm{CCM}_{1}$ gene. Korean J Pediatr. 2016; 59(6): 280-4.

67. Boulday G, Rudini N, Maddaluno L, Blecon A, Arnould M, Gaudric A, et al. Developmental timing of $\mathrm{CCM}_{2}$ loss influences cerebral cavernous malformations in mice. J Exp Med. 2011; 208(9): 1835-47.

68. Bravi L, Rudini N, Cuttano R, Giampietro C, Maddaluno L, Ferrarini L, et al. Sulindac metabolites decrease cerebrovascular malformations in $\mathrm{CCM}_{3}-$ knockout mice. Proceedings of the National Academy of Sciences of the United States of America. 2015; 112(27): 8421-6.

69. He Y, Zhang H, Yu L, Gunel M, Boggon T), Chen H, et al. Stabilization of VEGFR2 signaling by cerebral cavernous malformation 3 is critical for vascular development. Sci Signal. 2010; 3(116): ra26.

70. Maddaluno L, Rudini N, Cuttano R, Bravi L, Ciampietro C, Corada M, et al. EndMT contributes to the onset and progression of cerebral cavernous malformations. Nature. 2013; 498(7455): 492-6.

71. Bravi L, Malinverno M, Pisati F, Rudini N, Cuttano R, Pallini R, et al. Endothelial Cells Lining Sporadic Cerebral Cavernous Malformation Cavernomas Undergo Endothelial-to-Mesenchymal Transition. Stroke; a journal of cerebral circulation. 2016; 47(3): 886-90.
72. Bryan BA, D'Amore PA. What tangled webs they weave: Rho-GTPase control of angiogenesis. Cell Mol Life Sci. 2007; 64(16): 2053-65.

73. Pantoni L. Cerebral small vessel disease: from pathogenesis and clinical characteristics to therapeutic challenges. Lancet Neurol. 2010; 9(7): 689-701. 74. Borikova AL, Dibble CF, Sciaky N, Welch CM, Abell AN, Bencharit S, et al. Rho kinase inhibition rescues the endothelial cell cerebral cavernous malformation phenotype. J Biol Chem. 2010; 285(16): 11760-4.

75. Glading A, Han J, Stockton RA, Ginsberg MH. KRIT-1/CCM1 is a Rap effector that regulates endothelial cell cell junctions. J Cell Biol. 2007; 179(2): 247-54.

76. Stockton RA, Shenkar R, Awad IA, Ginsberg MH. Cerebral cavernous malformations proteins inhibit Rho kinase to stabilize vascular integrity. I Exp Med. 2010; 207(4): 881-96.

77. Whitehead KJ, Chan AC, Navankasattusas S, Koh W, London NR, Ling J, et al. The cerebral cavernous malformation signaling pathway promotes vascular integrity via Rho GTPases. Nat Med. 2009; 15(2): 177-84.

78. Zheng X, Xu C, Smith AO, Stratman AN, Zou Z, Kleaveland B, et al. Dynamic regulation of the cerebral cavernous malformation pathway controls vascular stability and growth. Dev Cell. 2012; 23(2): 342-55.

79. Zhou Z, Tang AT, Wong WY, Bamezai S, Coddard LM, Shenkar R, et al, Cerebral cavernous malformations arise from endothelial gain of MEKK3 KLF2/4 signalling. Nature. 2016; 532(7597): 122-6.

80. Ceibprasert S, Pongpech S, Jiarakongmun P, Shroff MM, Armstrong DC Krings T. Radiologic Assessment of Brain Arteriovenous Malformations: What Clinicians Need to Know. RadioGraphics. 2010; 30(2): 483-501.

81. Hernesniemi JA, Dashti R, Juvela S, Vaart K, Niemela M, Laakso A. Natura history of brain arteriovenous malformations: a long-term follow-up study of risk of hemorrhage in 238 patients. Neurosurgery. 2008; 63(5): 823-9; discussion 9-31.

82. Lazar RM, Connaire K, Marshall RS, Pile-Spellman J, Hacein-Bey L, Solomon RA, et al. Developmental deficits in adult patients with arteriovenous malformations. Arch Neurol. 1999; 56(1): 103-6.

83. Hara H, Burrows PE, Flodmark O, Terbrugge K, Humphreys R. Neonatal superficial cerebral arteriovenous malformations. Pediatr Neurosurg. 1994; 20(2): 126-36.

84. Turjman F, Massoud TF, Sayre JW, Vinuela F, Guglielmi C, Duckwiler C. Epilepsy associated with cerebral arteriovenous malformations: a multivariate analysis of angioarchitectural characteristics. AJNR Am J Neuroradiol. 1995; 16(2): 345-50.

85. Darsaut TE, Magro E, Centric $\mid C$, Batista AL, Chaalala C, Roberge D, et al. Treatment of Brain AVMs (TOBAS): study protocol for a pragmatic randomized controlled trial. Trials. 2015; 16: 497.

86. 8Sousa EC, Teixeira MJ, Piske RL, Albuquerque LS, Correa S, Benabou S, et al. The Role of Preradiosurgical Embolization in the Management of Crades III, IV, and V Arteriovenous Malformations. Front Surg. 2016; 3: 37

87. Renieri L, Consoli A, Scarpini G, Grazzini G, Nappini S, Mangiafico S. Double arterial catheterization technique for embolization of brain arteriovenous malformations with onyx. Neurosurgery. 2013; 72(1): 92-8.

88. Lai LF, Chen JX, Zheng K, He XY, Li XF, Zhang X, et al. Posterior fossa brain arteriovenous malformations: Clinical features and outcomes of endovascular embolization, adjuvant microsurgery and radiosurgery. Clin Neuroradiol. 2016. 89. Huo X, Jiang Y, Lv X, Yang H, Zhao Y, Li Y. Camma Knife surgical treatment for partially embolized cerebral arteriovenous malformations. I Neurosurg. 2016; 124(3): 767-76.

\section{Acknowledgments}

None.

Conflict of Interest Statement at Funding

No financial relationships relevant to this article to disclose. No conflicts of interest to disclose.

\section{Author Contributions}

Conception and design the work/idea: KE, FH, SG. Collection of data/obtaining results: KE. Analysis and interpretation of data: KE, FH, SG. Writing the manuscript KE. Approval of the final version: $\mathrm{KE}, \mathrm{FH}, \mathrm{SG}$.

Cite as:

Eliahu K, Hofman F, Giannotta S. A Systematic Review of Cerebral Arteriovenous Malformation Management. Int J Med Students. 2017 MayAug;5(2):74-80. 